\title{
Effect of Nano-Fluid Jet Impingement on Heat Transfer of Surfaces with Different Shapes
}

Ibrahim Nabil Ewis ${ }^{1}$, Sayed Abdel Mageed ${ }^{2}$, Mohamed El-Morsi ${ }^{3}$ and Osama Sharaf ${ }^{4}$ 1Department of Mechanical Engineering,Faculty of Engineering, Suez Canal

University,Ismailia, Egypt.ibraheam_nabil@yahoo.com

2 Department of Mechanical Engineering,Faculty of Engineering, Suez Canal

University,Ismailia, Egypt. Si_mageed@yahoo.com

3Department of Mechanical Engineering, School of Sciences and Engineering, The American University in Cairo, Cairo, Egypt,Melmorsi@aucegypt.edu

4 Department of Mechanical Engineering,Faculty of Engineering, Suez Canal University,Ismailia, Egypt.osamasharaf@eng.suez.edu.eg

\section{Abstract}

This study experimentally investigates heat transfer enhancement of an impinging free liquid jet on a hot surface of copper plate with different shapes, by replacing the base fluid, distilled water with $\mathrm{Al}_{2} \mathrm{O}_{3}$ nanofluid $(10 \mathrm{~nm})$, different shapes of heated surface of copper plate (Flat, Concave, Convex Wavedand Corrugated), different impingement Reynolds numbers $R e_{i}$ ranging from $(7,565$ to nearly 18,460$)$, five nanoparticles mass concentrations $(0 \%, 0.2 \%$, $0.5 \%, 1 \%$ and $2 \%$ ) were studied using distilled water and $\mathrm{AL}_{2} \mathrm{O}_{3}$ nanofluid jet impingement. The results of the current experiments show that increasing the volume flow rate of the cooling fluid improves the heat transfer between the free liquid jet and the hot copper plate.Moreover, using nanofluid jet enhances the heat transfer.Additionally, increasing the surface area enhances the heat transfer between the cooling fluid and the hot plate and decreases the cooling time.Finally, it was noted that surface shape, impingement Reynolds number and nanofluid concentration affect the heat transfer enhancement processsignificantly.The accumulative effect of using nanafluid jet $2 \%$ with corrugated surface with higher flow rate on Nusselt number can reach $185 \%$. On the other hand, using a dispersant for the nanofluid as polyethylene glycol keeps the nanofluid suspension and prevents agglomeration, but reduces its heat transfer enhancement effect.

Keywords:Nanofluid, Heat Transfer, Surface Shapes, Impingement Jet.

Corresponding Author:Ibrahim Nabil Ewis

\section{INTRODUCTION}

Heat transfer augmentation represents an active and important field of engineering research due to its contribution towards the evolution of highly efficient cooling technologies to meet continuous increase in demand in order to develop an efficacious designs of thermal equipment [1]. Heat transfer enhancement techniques are very important to save energy. In the past decades, heat transfer enhancement technology has been developed and widely applied [2]. As cooling is one of the essential technical challenges that faces many diverse industries, including transportation, microelectronics and manufacturing [3], this raises the need for new and advanced coolants with improved performance. Heat transfer can be enhanced by employing various techniques such as increasing either the heat transfer surface or the heat transfer coefficient between the fluid and the surface that allow high heat transfer rates in a small volume. Rough surfaces or extended surfaces are used for the purpose of 
increasing the effective surface area that can achieve a heat transfer enhancement of up to $65 \%$ [4].

Further theoretical and experimental research investigations were needed to understand the heat transfer characteristics of nanofluids. It has been found that significant enhancement of heat transfer performance was observed in comparison with pure water. This enhancement was intensified with the increase in the Reynolds number and the nanoparticle concentration [5]. nanofluidshows great promise in enhancing heat transfer characteristics in applications such as electronics cooling, nuclear reactors, and engine cooling applications, although nanofluids cause erosion and clogging of the heat transfer channels [6,7]. Several investigations have revealed that the thermal conductivity of the fluid containing nanoparticles could be increased by more than $20 \%$ for the case of very low nanoparticles concentrations. [4]. Another experiment conveyed that the use of nanofluids in a varied range of applications appears promising, but the development of this field may face numerous challenges $[8,9]$.

Impinging jets have received considerable attention during the last decade. Impinging liquid jet is an established technique to provide high local heat transfer coefficient between the impinged liquid and a surface. The use of jet impingement as a high performance technique for local heating or cooling a surface has become a well-established method because of its high heat transfer rates and its simplicity in application to a variety of industries [10]. The Combining the liquid jet impingement and the nanofluid technologies is thought to capture the advantages of both and consequently enhances the heat transfer significantly [11].

There are various parameters that influence the heat transfer in the jet impingement process including the heat flux, flow rate, inlet pressure, nozzle size, working medium properties and heating surface shape [12]. Using nanofluids (Specially $\mathrm{Al}_{2} \mathrm{O}_{3}$-water nanofluids) as coolant was investigated experimentally, numerically, and also mathematically and it was found that the amount of heat transfer increase with the use of nanofluids compared with water as base fluid especially with the increase of Reynolds number and nanoparticle volume fraction [13]. Another investigation revealed that water-based nanofluids of $29 \mathrm{~nm}$ copper oxide $(\mathrm{CuO})$ and $36 \mathrm{~nm}$ $\mathrm{Al}_{2} \mathrm{O}_{3}$ nanoparticles lead to a range of effective thermal conductivity improvements from $30 \%$ to $52 \%$ for nanofluidCuO/Distilled water, and $8 \%$ to $30 \%$ for nanofluid $\mathrm{Al}_{2} \mathrm{O}_{3} /$ Distilled water, in case of volume fractions of $6 \%$ and $10 \%$, respectively [14].Nguyen and his colleagues had experimentally studied the heat transfer performance of water- $\mathrm{Al}_{2} \mathrm{O}_{3}$ nanofluid and reported that using $5 \%$ particle volume fraction of the nanofluid provides a heat transfer enhancement of up to $72 \%$ compared with water [15].

Increasing the heat transfer efficiency of electronic devices is desirable. There are numerous methods to increase the heat transfer efficiency. Some of these methods include using extended surfaces, application of vibration to the heat transfer surface and the usage of microchannels. Heat transfer efficiency can be improved by changing the thermal conductivity of the cooling fluid. Commonly used heat transfer base fluids such as water and ethylene glycol have relatively low thermal conductivities, when compared to the thermal conductivity of different solids. High thermal conductivity of these solids can be used to enhance the thermal conductivity of the base fluid by adding small solid particles to base fluid [16, 17].

Nguyen et al., performed an experiment investigation on the heat transfer characteristic of $\mathrm{Al}_{2} \mathrm{O}_{3}$-water nanofluids with different volume fractions in a confined and submerged impinging jet on a flat, horizontal and circular heated surface. They found that the highest surface heat transfer coefficients were obtained with an intermediate nozzle-to-surface distance of $5 \mathrm{~mm}$ and a $2.8 \%$ particle volume fraction nanofluid [18]. Tie et al., experimentally investigated the heat transfer characteristics of $\mathrm{CuO}$-water nanofluids of volume fraction varying from $0.17 \%$ to $0.64 \%$ flowing through the multiple jet arrays impingement cooling system. The addition of nanoparticles can remarkably improve the heat 
transfer behaviors of the base fluid and the heat transfer coefficient increases with the increasing of volume fraction of nanoparticles. it is clear that compared with the case of using nanofluids without any addition of dispersant, the nanofluid with dispersant led to a great deterioration on impingement heat transfer coefficient and even the heat transfer coefficients were smaller than that of the base liquid [19].

Jet impingement cooling is a tool of heat transfer via means of collision of fluid molecules on to a surface. The impinging jet is defined as a high-velocity jet of cooling fluid enforced through a hole or slot which impinges on the surface for cooling, which leads to high heat transfer rates between the wall and the cooling fluid. Heat transfer occurs due to the collision of high velocity fluid molecules on the surface [20]. Zeitoun and Alicarried out an experimental investigation on the heat transfer of alumina-water nanofluid jet on a horizontal circular round surface. The results indicated that using the nanofluid enhanced the $N u$ up to $100 \%$ for some higher concentrations [21]. Jaberi, et al., performed an experimental study to investigate the convective heat transfer coefficient of $\mathrm{Al}_{2} \mathrm{O}_{3}$ /water nanofluid using impingement of a fluid jet on a flat circular disk. The maximum enhancement of the average nanofluid heat transfer coefficient in comparison with water is about $50 \%$ for $R e=4200$ [22] Nayak et al., experimentally assessed $\mathrm{Al}_{2} \mathrm{O}_{3}$ and water- $\mathrm{TiO}_{2}$ jet on hot steel surface. Experimental data were generated for nanofluids with $\mathrm{Al}_{2} \mathrm{O}_{3}$ and $\mathrm{TiO}_{2}$ nanoparticle weight concentrations of $0.01 \%, 0.03 \%, 0.05 \%$ and $0.07 \%$. They found that the nanofluid prepared with $\mathrm{Al}_{2} \mathrm{O}_{3}$ nanoparticles provided better heat transfer characteristics as compared to that of $\mathrm{TiO}_{2}$ and DI water [23]. Jaware and Bhagatexperimentally investigated the heat transfer and fluid flow due to the impingement of vertical circular single jet on a horizontal heated surface. The experimental results indicated that the local heat transfer coefficient at the stagnation point was more by $50 \%$ as compared to the heat transfer coefficient at the outermost point[24].

Teamah, et al., investigated numerically and experimentally the flow structure and heat transfer of a nanofluid jet normally impinging on a flat plate. $\mathrm{Al}_{2} \mathrm{O}_{3}$-water nanofluid was used as the working fluid. The results showed that a good agreement was found between the numerical and experimental results. At a concentration of $10.0 \%$ and $R e=24,000$ the heat transfer coefficient increased by $62 \%$ compared with the pure water. The CuOnanofluid increased the heat transfer by $8.9 \%$ and $12 \%$ compared to aluminium and titanium nanofluid, respectively [25]. Huang and Jang numerically investigated the impingement heat transfer features of nanofluids. They observed that the average Nusselt number increased with increasing the nanoparticle concentrations and Reynolds number [26].

Roy, et al., numerical studied the heat transfer performance of a liquid impingement jet using $\gamma-\mathrm{Al}_{2} \mathrm{O}_{3}$ nanoparticles suspended in water. They indicated a considerable improvement in heat transfer rates (up to $100 \%$ in local heat transfer coefficient) even with small particle volume fractions [27]. Gherasim, et al., investigated numerically the heat transfer enhancement and pumping power in an impingement jet using suspended nanoparticles of $\mathrm{Al}_{2} \mathrm{O}_{3}$-water. They reported that the mean Nusselt number increased with particle volume fraction and Reynolds number and decreased with an increase in nozzle-to-disc spacing[28]. This paper investigates experimentally heat transfer enhancement of an impinging free liquid jet with different volume flow rate $(0.6-1.4 \mathrm{l} / \mathrm{min})$ on a copper plate surface with different shapes(Flat, Corrugated, Waved, Convex, Concave) by replacing the base fluid with different mass concentration of nanofluids $\mathrm{Al}_{2} \mathrm{O}_{3}(0 \%-2 \%)$.

\section{MATERIALS AND METHODS \\ Experimental setup}

The experimental test rig consists of three parts; fluid cycle, heating system and data acquisition system as shown in figure 1 and photo 1 


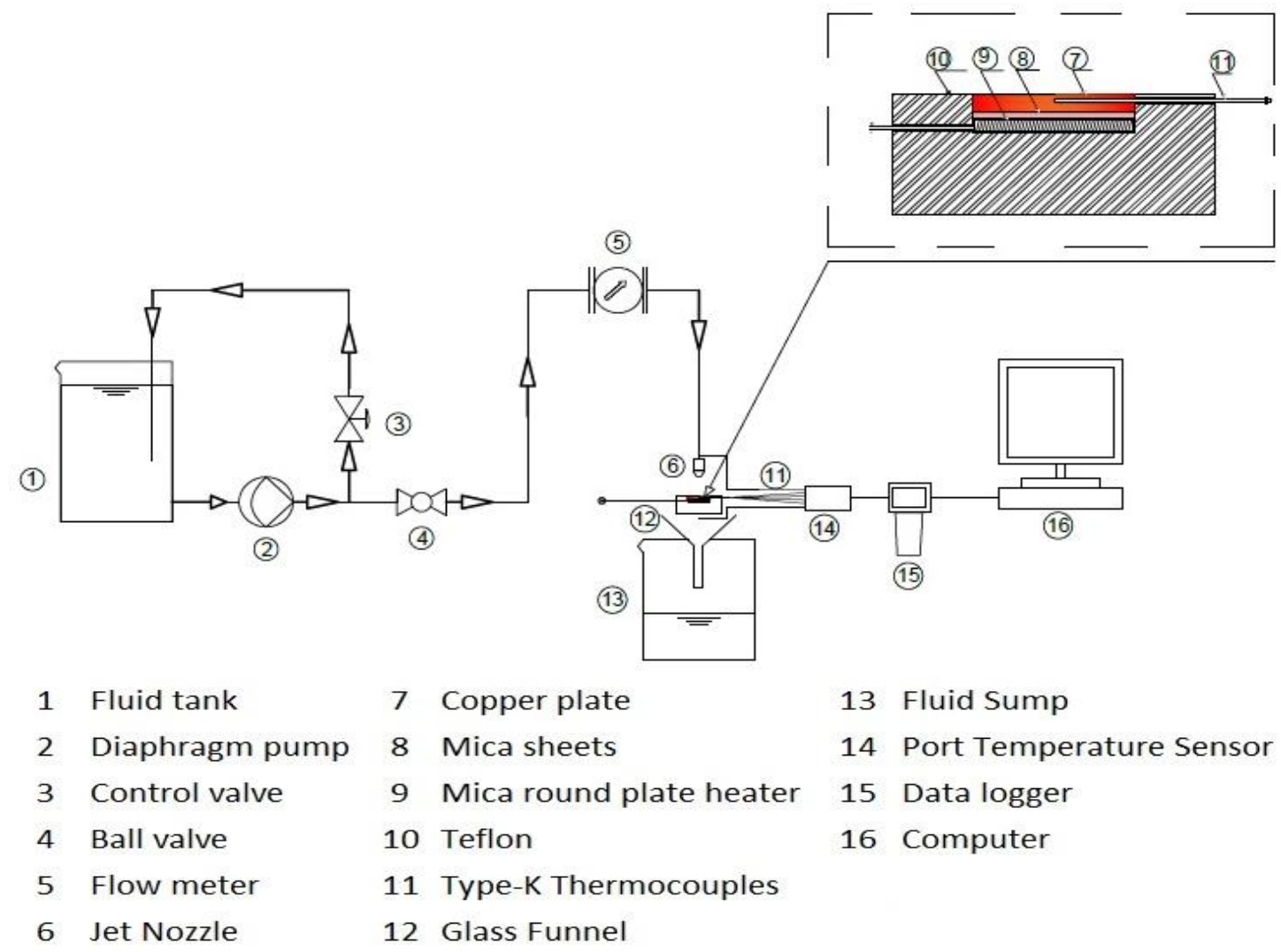

Figure 1 : Schematic diagram of the test rig

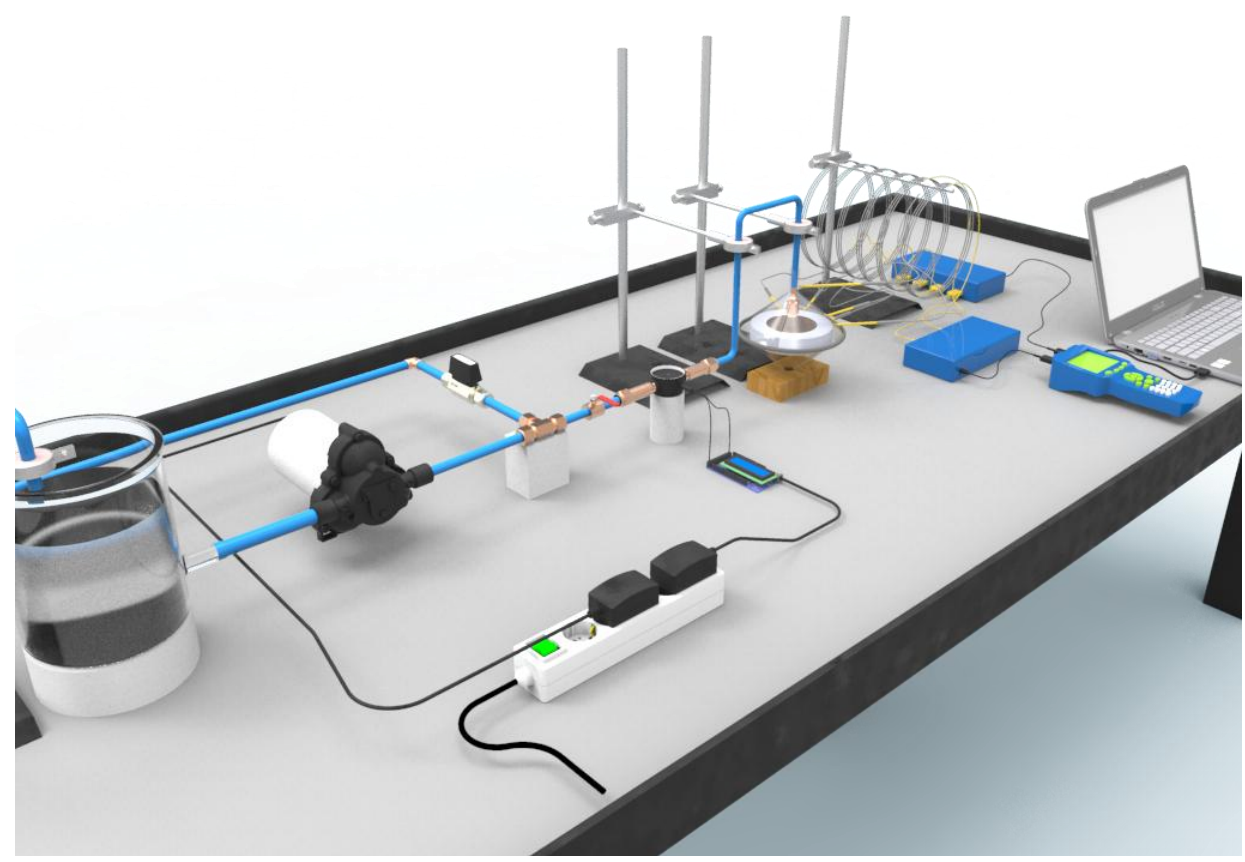

Photo 1: A photographic view for the experiment test rig

Fluid Cycle: which includes a cylindrical tank (1) that is connected to suction line of Diaphragm pump (2) maximum outlet pressure of the pump is $862 \mathrm{KPa}$ (125 psi), discharge line is connected to control valve (3) to recycling to fluid tank, the ball valve (4) control the measuring range of flow to Hall effect water flow meter/sensor (5), The cooling fluid 
(distilled water or nanofluids) flows through the jet nozzle (6) The nozzle is $25 \mathrm{~mm}$ long and $2 \mathrm{~mm}$ in diameter. The vertical distance between that nozzle and the heated surface, the nozzle-to-plate spacing, is carefully set to $50 \mathrm{~mm}$ from the surface of the copper plate and verified rigorously before and also after any test using prefabricated precision gauges, glass funnel (12) to collect the impinged liquid in the fluid sump (13).

Heating system:as shown in figure 2, which consists of heated copper plates with different geometries as hot surfaces to be cooled with the cooling fluid. The studied geometries are flat,concave, convex, waved andcorrugated, The plates are $50 \mathrm{~mm}$ in diameter and $5-6 \mathrm{~mm}$ thick (7), mica laminated sheets placed on the heater are used to ensure that heat is distributed equally on the hot plate (8), The plates are heated by a $220 \mathrm{~V}$ and $150 \mathrm{~W}$. Mica round plate heater(9) is connected to a DC Power supply to provide electric current, the heating system is thermally insulated by using thermal Teflon (10).

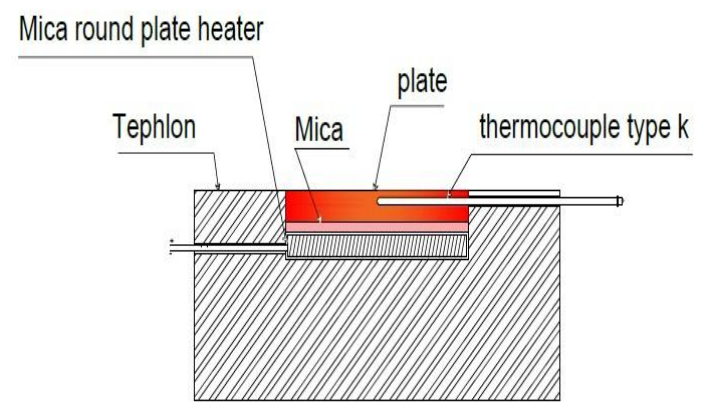

Figure 2 : heating system

Data acquisition system: which consists of six Type-K thermocouples, Four Type-K thermocouples probes (11), are used to measure the temperature of the heated surface at the center and at a distance $25,16,8$ and $1 \mathrm{~mm}$, from the outer edge that represent $\mathrm{T} 1$ stagnation point, T2 near impingement region,T3 boundary region and $\mathrm{T} 4$ periphery region respectivelyas shown in figure 3 .

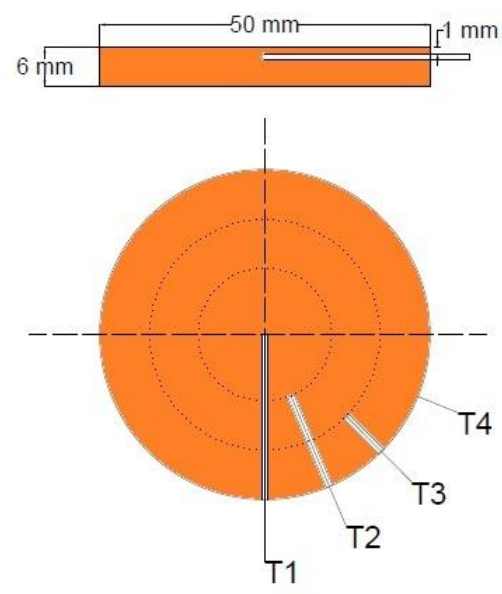

Figure 3 : thermocouple locations

The thermocouples are connected to a temperature sensor and have a measurement range $270^{\circ} \mathrm{C}-1260^{\circ} \mathrm{C}$, uncertainty $\pm 2.2^{\circ} \mathrm{C}$ and with error level $\pm 1.1^{\circ} \mathrm{C}$. Also, two Type-K temperature probes are placed before the nozzle and exit port of test rig (fluid sump) to measure the temperature of the fluid before and after the impingement to estimate the temperature difference of the cooling fluid, two 4-port Type $\mathrm{K}$ differential temperature measurement (14), Xplorer GLX data logger (15) connected to a computer (16). 


\section{Nanofluid characterization and preparation \\ Characterization of the nanoparticle $\mathrm{AL}_{2} \mathrm{O}_{3}$}

The characterization of aluminum oxide nanoparticles is carried out in Egypt nanotechnology center using transmission electron microscopy (TEM), X-ray powder diffraction (XRD), scanning electron microscopy (SEM), atomic force microscopy (AFM), and Raman spectroscopy. The most important characterization parameters:agglomeration, concentration, size distribution, size, shape, surface charge, surface area, pore size, pore volume, surface roughness, surface waviness and composition.

\section{Transmission electron microscopy (TEM)}

Alumina nanoparticles of $10 \mathrm{~nm}$ particle size were used the image used by transmission electron microscopy is shown in figure 4.

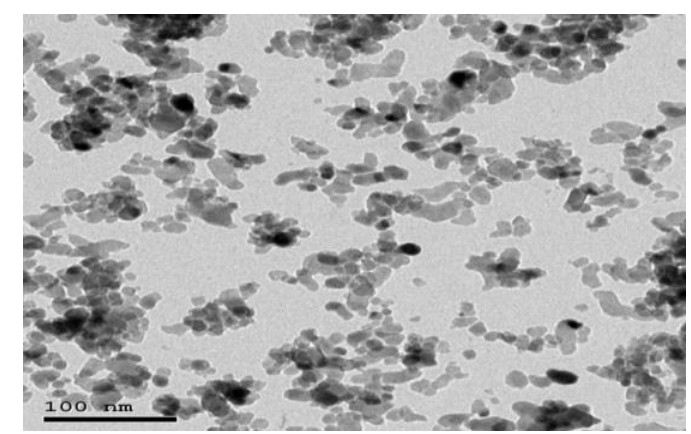

Figure 4 : TEM image of the synthesized $\mathrm{Al}_{2} \mathrm{O}_{3}$ nanoparticles

\section{X-ray powder diffraction (XRD)}

The average crystallite size of the alumina samples is calculated, utilizing the XRD instrument, using the Sherrer's formula, as shown in Equation 1.

$$
D=\frac{K \lambda}{\beta \cos \theta}
$$

Where $D$ is the crystallite size, $K$ is the Sherrer's constant $(K=0.9), \lambda$ is the wavelength, $\beta$ is the peak width at half height, and $\theta$ is the diffraction angle. Figure 5, shows the X-ray powder diffractogram for the tested sample. Peak positions occur where the crystal lattice diffracts the X-ray beam. The X-ray powder diffractogram shows that the diffraction peaks appear at $33^{\circ}, 37^{\circ}, 46^{\circ}$ and $67^{\circ}$ of alumina nanoparticle. The average sizes of the nanoalumina are estimated from the half-height width of the strong peaks to be $1.826 \mathrm{~nm}$.

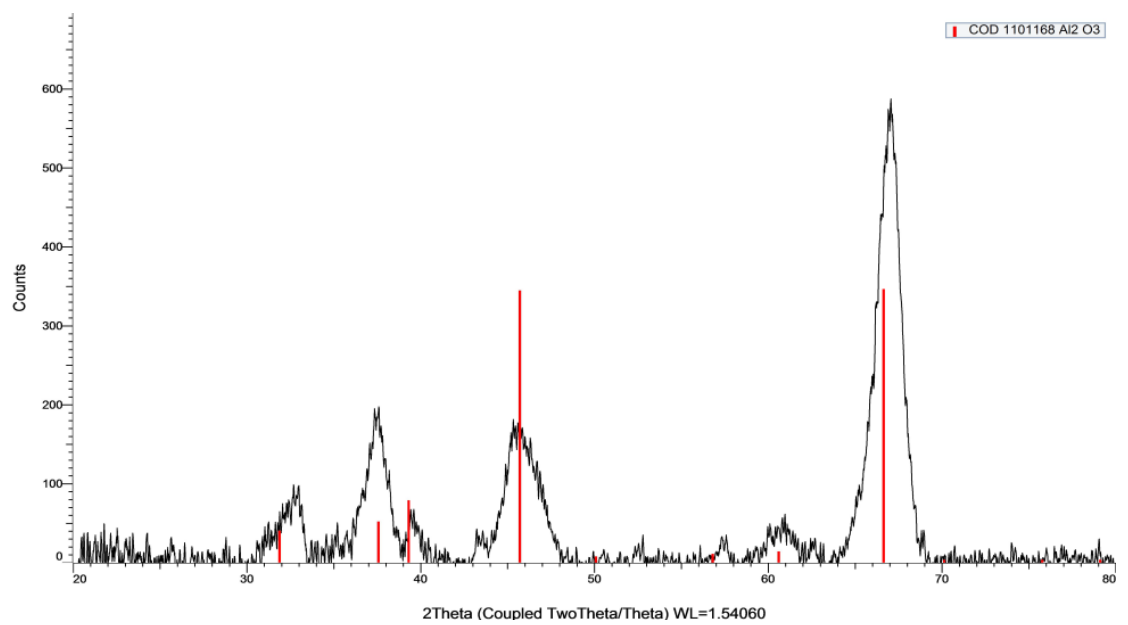

Figure 5: X-ray powder diffractogram of the synthesized nanoparticles 


\section{Scanning electron microscopy (SEM)}

SEM image provides information on the distribution, pattern and size of the nanoparticles. Figure6, shows the morphology and particle size of the synthesized nanoparticles that are characterized by the SEM.

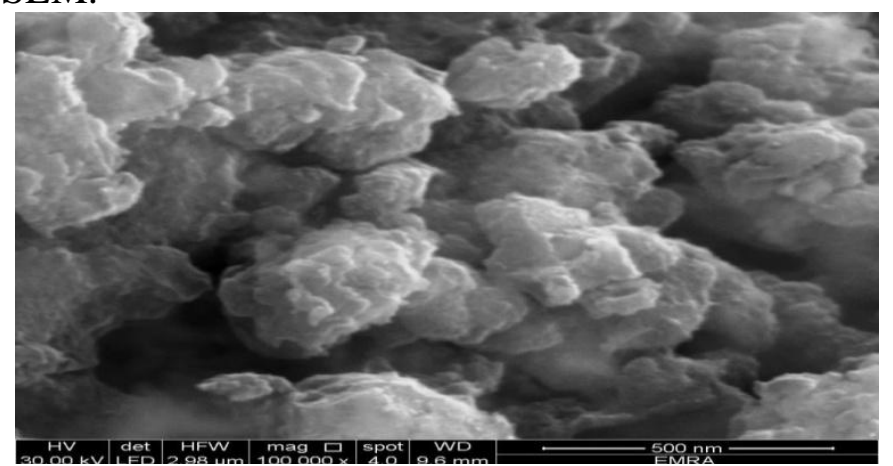

Figure6: SEM image micrographs of the synthesized nanoparticles

\section{Atomic force microscopy (AFM)}

The AFM is a three-dimensional topographic technique with a high atomic resolution to measure surface roughness. Figure7, shows the AFM topography of the synthesized nanoparticles. The AFM examination, as presented in table 1, reveals that the mean height of the roughness profile $\left(R_{c}\right)$ is $0.0136 \mu \mathrm{m}$. The root-mean-square (RMS) surface roughness is $0.00483 \mu \mathrm{m}$ which indicates that the present $\mathrm{Al}_{2} \mathrm{O}_{3}$ samples are relatively smooth on an atomic-scale.

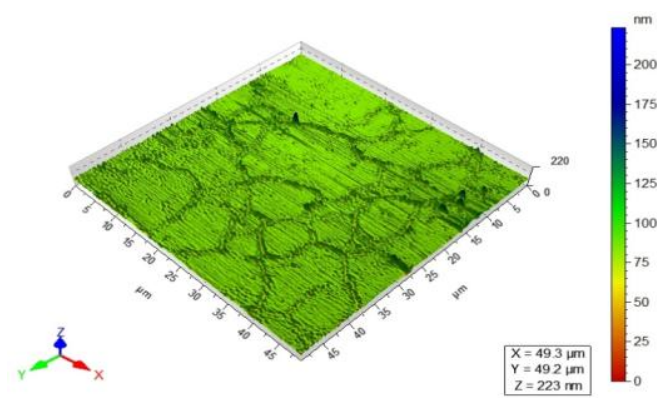

(a).

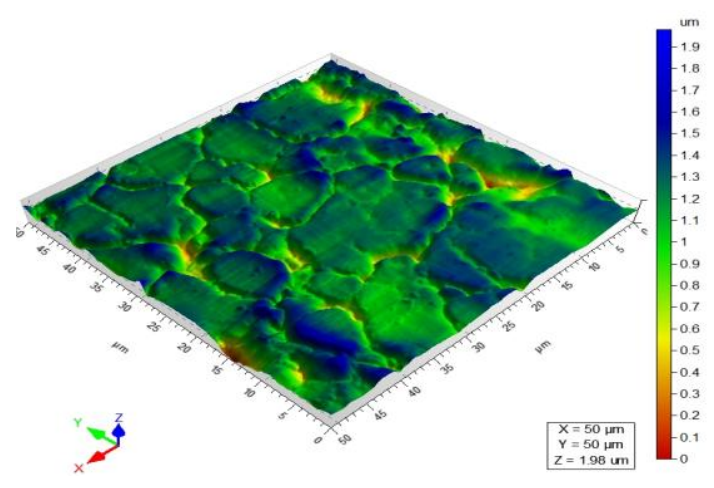

(c)
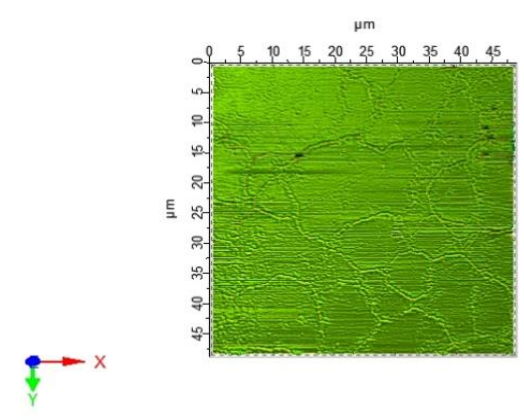

(b)

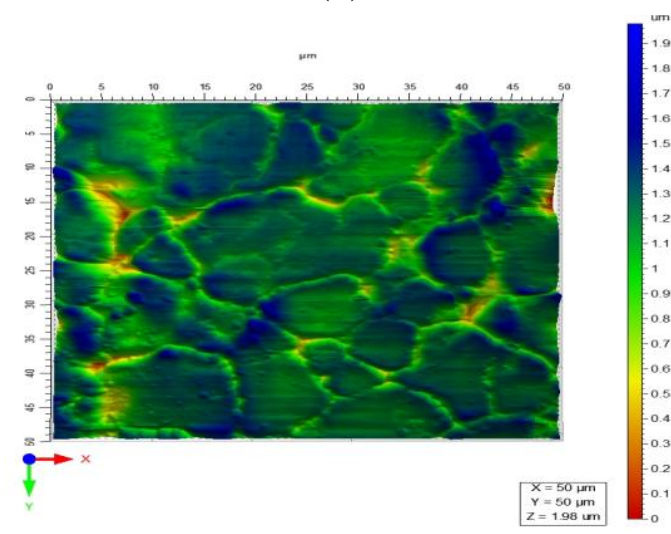

(d)

Figure7: AFM topography of the synthesized nanoparticles

(a) 3D AFM image for $\mathrm{AL}_{2} \mathrm{O}_{3}$ nanoparticles $(45 \times 45 \mu \mathrm{m})$

(b) AFM top view for $\mathrm{AL}_{2} \mathrm{O}_{3}$ nanoparticles $(45 \times 45 \mu \mathrm{m})$ (c) 3D AFM image for $\mathrm{AL}_{2} \mathrm{O}_{3}$ nanoparticles $(50 \times 50 \mu \mathrm{m})$

(d) AFM top view for $\mathrm{AL}_{2} \mathrm{O}_{3}$ nanoparticles $(50 \times 50 \mu \mathrm{m})$ 
Table 1: Amplitude parameter and roughness profile

\begin{tabular}{|l|c|c|}
\hline \multicolumn{3}{|c|}{ Amplitude parameter and roughness profile } \\
\hline Maximum peak high of the roughness profile & $R_{p}$ & $0.0183 \mu \mathrm{m}$ \\
\hline Maximum valley depth of the roughness profile & $R_{v}$ & $0.0224 \mu \mathrm{m}$ \\
\hline Maximum height of roughness profile & $R_{z}$ & $0.0407 \mu \mathrm{m}$ \\
\hline Mean height of the roughness profile elements & $R_{c}$ & $0.0136 \mu \mathrm{m}$ \\
\hline Total height of roughness profile & $R_{t}$ & $0.0407 \mu \mathrm{m}$ \\
\hline Arithmetic mean deviation of the roughness profile & $R_{a}$ & $0.00318 \mu \mathrm{m}$ \\
\hline Root-Mean-Square (RMS) deviation of the roughness profile & $R_{q}$ & $0.00483 \mu \mathrm{m}$ \\
\hline Skewness of the roughness profile & $R_{s k}$ & $-0.49 \mu \mathrm{m}$ \\
\hline Kurtosis of the roughness profile & $R_{k u}$ & $6.70 \mu \mathrm{m}$ \\
\hline
\end{tabular}

\section{Raman spectroscopy}

A Raman spectrometer is used to obtain detailed information about the molecular structure of the metal oxide. Raman spectra show the crystalline nature of the nanoparticles. In an amorphous state, the Raman bands are quite broad but often can be derived from one of the crystalline forms of the same material. The results of the Raman spectroscopy are summarized in table2.

Table 2: Results of the Raman spectra of the synthesized nanoparticles

\begin{tabular}{|c|c|}
\hline Position & Raman shift $\mathbf{~ m}^{-1}$ \\
\hline 1 & 59.74 \\
\hline 2 & 364.09 \\
\hline 3 & 473.49 \\
\hline 4 & 1455.4 \\
\hline 5 & 1518.5 \\
\hline 6 & 1716.62 \\
\hline 7 & 1780.68 \\
\hline 8 & 1817.53 \\
\hline 9 & 2328.84 \\
\hline 10 & 2895.34 \\
\hline
\end{tabular}

\section{Preparation of the nanofluid}

The two-step method was used for preparation as commercial nanoparticles were purchased in dry powder and dispersed in distilled water. In this case, initially, the $\mathrm{AL}_{2} \mathrm{O}_{3}$ nanoparticles were mixed in the distilled water then submitted to a sonication treatment for 30 minute to disperse all the material and to break the agglomerates.

Thermo physical properties of alumina nanoparticlesin table 3 


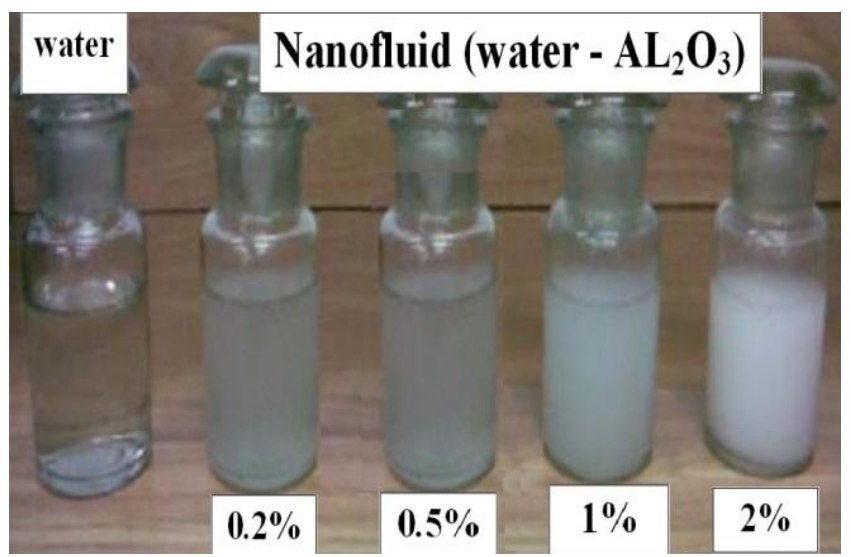

Photo $2: \mathrm{AL}_{2} \mathrm{O}_{3}$ suspension in distilled water

Table3: Thermo-physical properties of alumina nanoparticles

\begin{tabular}{|l|l|}
\hline \multicolumn{1}{|c|}{ Property } & \multicolumn{1}{c|}{ Value } \\
\hline Particle size & $10 \mathrm{~nm}$ \\
\hline Particle shape & Spherical \\
\hline Appearance & white powder \\
\hline $\mathrm{pH}$ value & 6.6 \\
\hline Density $\left(\rho_{\mathrm{np}}\right)$ & $3.97 \mathrm{gm} / \mathrm{cm}^{3}$ \\
\hline Specific surface area & $15-20 \mathrm{~m}^{2} / \mathrm{gm}$ \\
\hline High purity & $99 \%$ \\
\hline Thermal conductivity $(\mathrm{k})$ & $36 \mathrm{~W} / \mathrm{m}-\mathrm{K}$ \\
\hline Specific heat coefficient $\left(C_{\mathrm{np}}\right)$ & $880 \mathrm{~J} / \mathrm{kg}-\mathrm{K}$ \\
\hline
\end{tabular}

\section{Experiment procedure and investigated parameters}

The experimental investigation passes through 6 steps to assess different parameters.

Step 1: to assess the effect of different volume flow rates, $\dot{\forall}$ from $(0.6$ to $1.41 / \mathrm{min})$ on the heat transfer enhancement of the flat copper plate using distilled water (mass concentration $0 \%$ ) at target temperature $175^{\circ} \mathrm{C}$.

Step 2: to assess the effect of different initial average plate temperatures, sometimes referred to as the target temperature, $\left(175^{\circ} \mathrm{C}, 150^{\circ} \mathrm{C}, 125^{\circ} \mathrm{C}, 100^{\circ} \mathrm{C}\right.$ and $\left.75^{\circ} \mathrm{C}\right)$ on the heat transfer enhancement of the flat copper plate using water (mass concentration $0 \%$ ) and $1.4 \mathrm{l} / \mathrm{min}$ flow rate.

Step 3: to assess the effect of different copper plate surfaces (flat, waved, corrugated, convex and concave) on the heat transfer enhancement of the copper plate using distilled water at best flow $1.4 \mathrm{l} / \mathrm{min}$ with target temperature $175^{\circ} \mathrm{C}$.

Step 4: to assess the effect of different copper plate surfaces (flat, waved, corrugated convex and concave) on the heat transfer enhancement of the copper plate using nanofluid $\mathrm{AL}_{2} \mathrm{O}_{3}$ with mass concentration $2 \%$ at $1.4 \mathrm{l} / \mathrm{min}$ flow rate and with target temperature $175^{\circ} \mathrm{C}$.

Step 5: to assess the effect of different mass concentrations of $\mathrm{AL}_{2} \mathrm{O}_{3}$ nanofluid $(0.2 \%, 0.5 \%$, $1 \% \& 2 \%$ ) on the heat transfer enhancement of best copper plate shape.

Step 6: to assess the effect of adding polyethylene glycol 600 (PEG 600) with different mass concentrations of $\mathrm{AL}_{2} \mathrm{O}_{3}$ nanofluid $(0.2 \%, 0.5 \%, 1 \% \& 2 \%)$ on the heat transfer enhancement of best copper plate shape. PEG 600 is added as surfactant which plays an important role in dispersing the nanoparticles into the base fluid and improves the stability of $\mathrm{AL}_{2} \mathrm{O}_{3} / \mathrm{de}$ ionized water nanofluids. 


\section{Theory and problem formulation}

A significant parameter for evaluating the heat transfer coefficients between the nanofluid jet and the target is $N u$. The magnitude and distribution of the heat transfer coefficient are found to be dependent on several parameters, including $\operatorname{Pr}, \operatorname{Re}, H / d, d$ and the physical geometry of the jets and the heated surface. Also, $N u$ depends on various thermo-physical properties of the nanofluid such as thermal conductivity, heat capacity, viscosity, the volume fraction of the suspended particles, and the dimension and shape of the particles.

\section{Thermo-physical properties of the nanofluid}

The mixture properties of nanofluids are usually expressed in terms of the mass concentration, $X$, as expressed by Equation2.

$X=\frac{m_{n p}}{m_{b f}+m_{n p}} \times 100$

Where $m_{b f}$ and $m_{n p}$ are the masse-+s of the base fluid and the nanoparticles, respectively. The mixture properties of the nanofluids are usually expressed in terms of the volume fraction, $\Phi$, or volume concentration, $\varphi$, (vol\%), as expressed by Equation3.

$\varphi=\frac{V_{n p}}{V_{b f}+V_{n p}} \times 100$

Where $V_{b f}$ and $V_{n p}$ are the volumes of the base fluid and the nanoparticles, respectively. The mass fraction $X$ can be converted to $\varphi$, as expressed by Equation4[21].

$\frac{1}{\rho_{n f}}=\frac{X}{\rho_{n p}}+\frac{(1-X)}{\rho_{b f}}$

Where $\rho_{n f}, \rho_{n p}$ and $\rho_{b f}$ are the densities of the nanofluid, the nanoparticles and the base fluid, respectively. For the distilled water- $\mathrm{Al}_{2} \mathrm{O}_{3}(10 \mathrm{~nm}$ particle diameter $)$ nanofluid studied, assuming a uniform particle volume fraction and knowing the constituent properties, the density of the mixture $\rho_{n f}$, can be evaluated using the equation,Equation5[29].

$\rho_{n f}=(1-\varphi) \rho_{b f}+\varphi \rho_{n p}$

The specific heat of the mixture $C_{n f}$ can be evaluated using the equation of, Equation6[29].

Error! Reference source not found.

$C_{n f}=(1-\varphi) C_{b f}+\varphi C_{m p} \quad(6)$

Where $C_{b f}$ and $C_{m p}$ are the volumes of the base fluid and the nanoparticles, respectively. The experimentally measured dynamic viscosity of the nanofluid $\mu_{n f}$ can be validated by using the equations Equation 7[30].

$\mu_{n f}=\mu_{b f}\left(123 \varphi^{2}+7.3 \varphi+1\right)$

Where $\mu_{b f}$ is the dynamic viscosity of the base fluid. The thermal conductivity of the nanofluid $k_{n f}$ is measured experimentally and can be calculated by using the equations of, Equation 8 [31].

$k_{n f}=k_{b f}\left(4.97 \varphi^{2}+2.72 \varphi+1\right)$

Where $k_{b f}$ is the thermal conductivity of the base fluid. The thermo-physical properties of the nanofluid are summarized

\section{Hydrodynamics of the problem}

The jet velocity at the nozzle exit, $V_{j}$ is obtained using the continuity equation at the nozzle exit. The jet velocity at the impingement point can be obtained by applying the energy equation between the nozzle exit and just before the impingement point $V_{i}$ as expressed by Equation 9.

$$
V_{i}=\sqrt{V_{j}^{2}-2 g H}
$$


Where $g$ and $H$ are the gravitational acceleration and nozzle-to-plate spacing, respectively. The jet impingement diameter $D_{i}$ just before the impingement is calculated from the continuity equation just before impingement in terms of the nozzle diameter $D_{j}$ as expressed by Equation 10.

$D_{i}=D_{j}\left(\frac{V_{j}}{V_{i}}\right)^{0.5}$

The impingement Reynolds number based on the jet impingement velocity and the diameter at the impingement point is given by Equation 11.

$\operatorname{Re}_{i}=\frac{\rho V_{i} D_{i}}{\mu}=\frac{V_{i} D_{i}}{\nu}$

Where $\rho$ is the density of the cooling fluid and $\mu$ is the dynamic viscosity of the cooling fluid.

\section{Heat exchange of the problem}

The average heat transfer coefficient $\bar{h}$ between the cooling fluid jet and the target disc with diameter $d$ is calculated via the average Nusselt number $\overline{N u}_{d}$ as given by Equation 12.

$\overline{N u}_{d}=\frac{\bar{h} d}{K}$

Where $k$ is the thermal conductivity of the cooling fluid. The average Nusselt number grows as the Reynolds number increases. Finally, the total electric input power $\dot{Q}$ is defined by heat balance Equation13[9], [15], [18], [19], [22], [25] and [28].

$\dot{Q}=\bar{h} A\left(\bar{T}_{s_{i}}-T_{f_{i}}\right)=\dot{m} C\left(T_{f_{o}}-T_{f_{i}}\right)$

Where $\dot{m}$ and $C$ are the mass flow rate and the specific heat of the cooling fluid, respectively. $\bar{T}_{s_{i}}, T_{f_{o}}$ and $T_{f_{i}}$ are the initial average temperature of the heated plate, the average temperature of the cooling fluid after impingement at outlet and the average temperature of the cooling fluid at the nozzle exit, respectively. The average heat transfer coefficient of the cooling fluid is calculated according to Equation 14.

$\bar{h}=\frac{q^{\prime \prime}}{\left(\bar{T}_{s_{i}}-T_{f_{i}}\right)}$

Where $q^{\prime \prime}$ is the heat flux calculated as $\dot{Q} / A$.

\section{Calibration and uncertainty analysis}

The thermocouples, temperature probes and data acquisition system are calibrated at freezing and boiling points. At the freezing point, the error in thermocouple readings is in the range from -0.2 to $0.1^{\circ} \mathrm{C}$. At the boiling point, the error in the thermocouple readings is in the range from 0.15 to $0.4^{\circ} \mathrm{C}$. Also, thermocouples were calibrated using a standard liquid thermometer and measuring water at temperature $50^{\circ} \mathrm{C}$ with an accuracy of $2^{\circ} \mathrm{C}$. This calibration ensured that all thermocouples' readings are accurate.

The uncertainties associated with different equipment used in the impingement jet experiment are enlisted in Table4, To find the uncertainties in the measurements of temperature, velocity, and time, propagation of error is performed. The uncertainty in jet velocity is calculated as $\pm 1.8 \%$, whereas the maximum uncertainty in temperature and time measurements is found to be $\pm 1.3^{\circ} \mathrm{C}$ and $\pm 0.07 \mathrm{~s}$, respectively. The accuracy of the remaining items of equipment is taken directly from the relevant technical specifications. 
Table 4: The measurement range, accuracy and error

\begin{tabular}{|l|c|c|c|}
\hline Equipment/sensors & $\begin{array}{c}\text { Measurement } \\
\text { range }\end{array}$ & $\begin{array}{c}\text { Accuracy } \\
(\mathbf{\pm})\end{array}$ & $\begin{array}{c}\text { Error } \\
( \pm)\end{array}$ \\
\hline Hall effect water flow meter & $0.3-10 \mathrm{l} / \mathrm{min}$ & $1 \%$ & $0.003 \mathrm{l} / \mathrm{min}$ \\
\hline Diaphragm pump & $0-8.5 \mathrm{bar}$ & $1 \%$ & $0.05 \mathrm{bar}$ \\
\hline Electrometer & $0-20 \mathrm{mils}$ & $1 \%$ & $0.01 \mathrm{mils}$ \\
\hline Mica round plate heater & $300{ }^{\circ} \mathrm{C}$ & \pm 0.5 & $1.0^{\circ} \mathrm{C}$ \\
\hline K-type thermocouple & $-270-1260^{\circ} \mathrm{C}$ & $2.2^{\circ} \mathrm{C}$ & $1.1^{\circ} \mathrm{C}$ \\
\hline Data acquisition system & $-10-135^{\circ} \mathrm{C}$ & $0.2^{\circ} \mathrm{C}$ & $0.1^{\circ} \mathrm{C}$ \\
\hline Thermocouple time response & & $0.06 \mathrm{~s}$ & $0.03 \mathrm{~s}$ \\
\hline Data acquisition system time response & & $0.01 \mathrm{~s}$ & $0.02 \mathrm{~s}$ \\
\hline
\end{tabular}

\section{EXPERIMENTAL RESULTS AND DISCUSSION:}

The results are divided into two sections. The first section presents the cooling curves; details of cooling time, the second section discusses the results of the enhancement of the heat transfer in terms of Nusseltnumber and the influence of the investigated parameters on Nusselt number.

\section{Cooling curves: -}

\section{The effect of the volume flow rate of the cooling fluid:-}

To select the best volume flow rate of the cooling fluid that enhances the heat transfer between the jet and the heated copper plate, the following figure summarizes the results of the investigated five volume flow rates of distilled water jet from ( 0.6 to $1.4 \mathrm{l} / \mathrm{min}$ ).

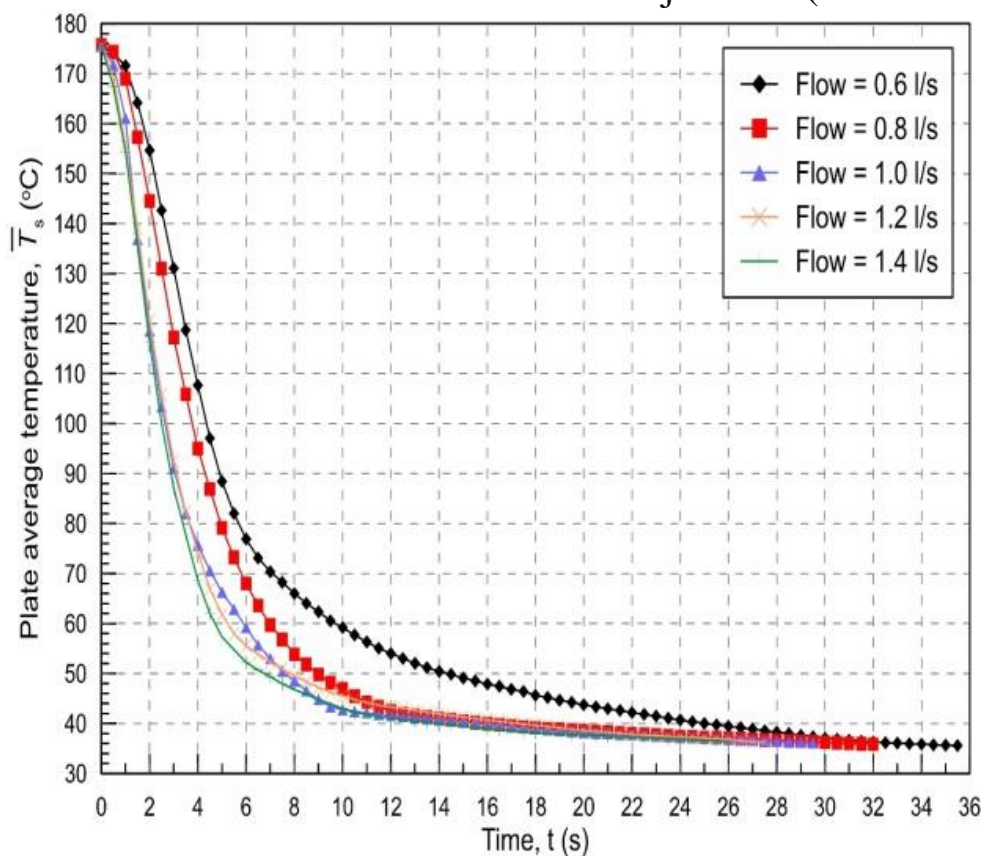

Figure8:Effect of volume flow rate on plate cooling, $\mathrm{X}=0, \& \overline{\mathrm{T}}_{\mathrm{S}_{\mathrm{i}}}=175^{\circ} \mathrm{C}$

Figure 8 shows that increasing the volume flow rate of the cooling fluid enhances the heat transfer between the cooling fluid and the plate. Increasing the volume flow rate decreases the cooling time.

The effect of the plate's surface geometry, using distilled water:-

Theeffect of the plate's surface geometry on the enhancement of the heat transfer between the jet and the heated plate. The following five plate surface geometries are examined: flat, 
concave, convex, waved and, corrugated, the following figure summarizes the results of the different geometries.

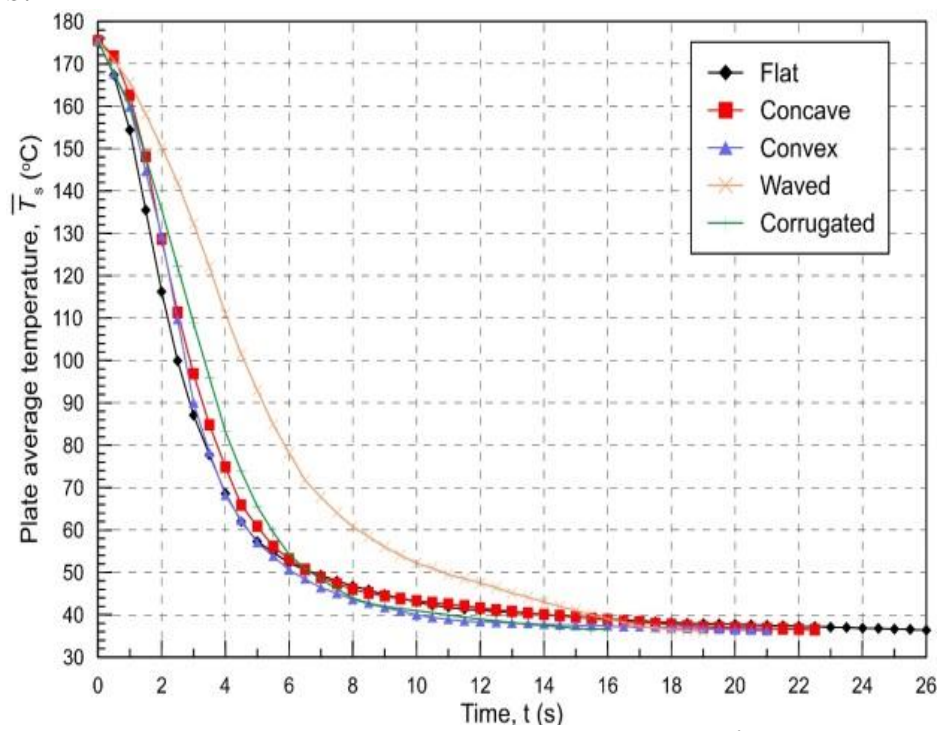

Figure9:Effect of plate geometry on plate cooling, $\mathrm{X}=0, \dot{\mathrm{V}}=1.4 \mathrm{1} / \mathrm{min} \& \overline{\mathrm{T}}_{\mathrm{s}_{\mathrm{i}}}=175^{\circ} \mathrm{C}$

Figure 9shows that increasing the surface area enhances the heat transfer between the cooling fluid and the plate. Also, increasing the surface area decreases the cooling time.

The effect of the plate's surface geometry, using $2 \% \mathrm{Al}_{2} \mathrm{O}_{3}$ concentration:-

Theeffect of the plate surface geometry on the enhancement of the heat transfer between the jet and the heated plate, while using the nanofluid with $\mathrm{Al}_{2} \mathrm{O}_{3}$ mass concentration of $2 \%$.

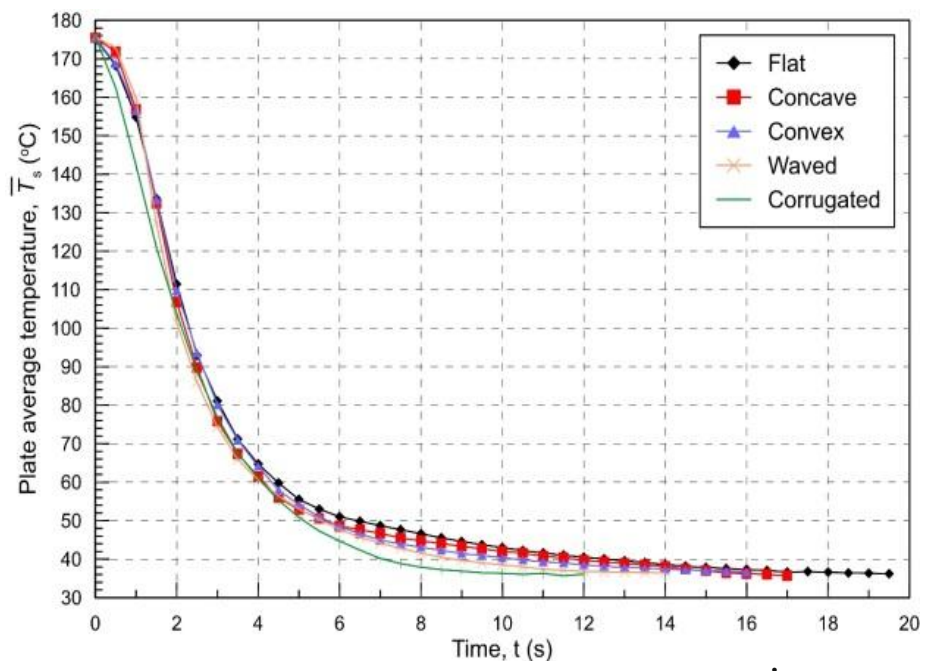

Figure 10:Effect of plate geometry on plate cooling, $X=2.0 \%, \dot{V}=1.41 / \mathrm{min} \& \overline{\mathrm{T}}_{\mathrm{s}_{\mathrm{i}}}=175^{\circ} \mathrm{C}$ Figure 10shows that adding the nanoparticles to the distilled water enhances the heat transfer between the cooling fluid and the plate.

\section{The effect of $\mathrm{Al}_{2} \mathrm{O}_{3}$ concentration:-}

Theeffect of mass concentration of the nanofluid on the enhancement of the heat transfer between the jet and the heated plate. The following four $\mathrm{Al}_{2} \mathrm{O}_{3}$ concentrations are examined: $0.2 \%, 0.5 \%, 1 \%$, and, $2 \%$. 


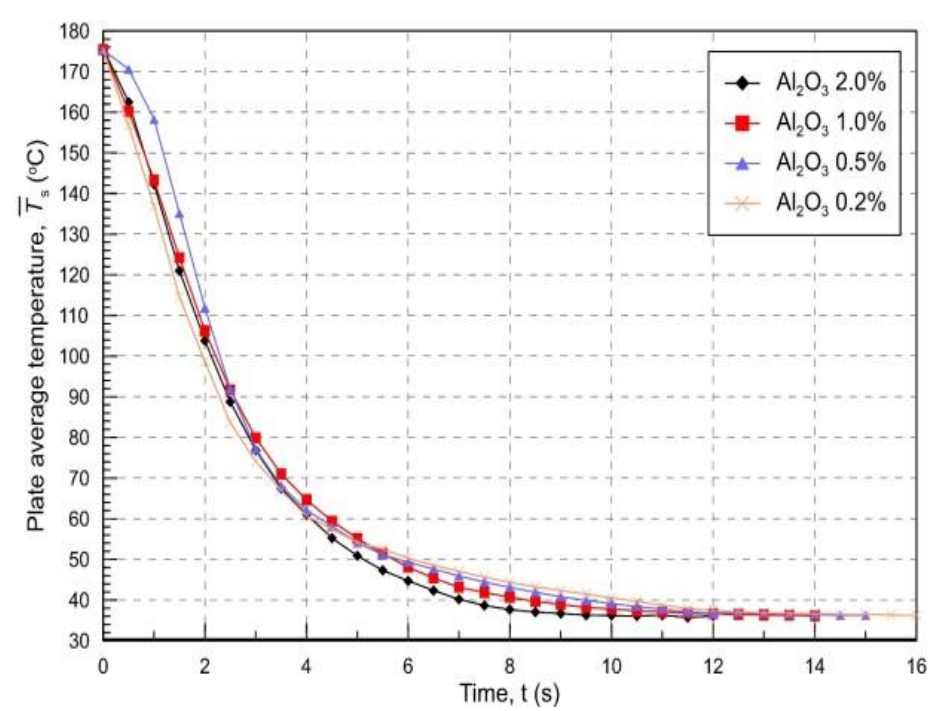

Figure 11:Effect of $\mathrm{Al}_{2} \mathrm{O}_{3}$ fraction on corrugated plate cooling, $\dot{\mathrm{V}}=1.4 \mathrm{l} / \mathrm{min} \& \overline{\mathrm{T}}_{\mathrm{S}_{\mathrm{i}}}=175^{\circ} \mathrm{C}$ Figure 11shows that increasing the concentration of the nanofluid enhances the heat transfer between the cooling fluid and the plate. Increasing the concentration of the nanofluid decreases the cooling time.

\section{The influence of investigated parameters on Nusselt number The influence of the volume flow rate of the cooling fluid:-}

Figure 12 shows that increasing volume flow rate increases $R e_{i}$ that enhances $\overline{N u}_{d}$. As the increase in $R e_{i}$ from 7565 to 18460 results in $36.8 \%$ enhancement in Nusselt number. This is because higher $R e_{i}$ increases turbulence. Subsequently, the boundary layer breaks away from the plate surface and mixes with the bulk of the cooling fluid further from the plate surface. The figure also compares the experimental results to the Teamah and Farahat's and Zeitoun model.

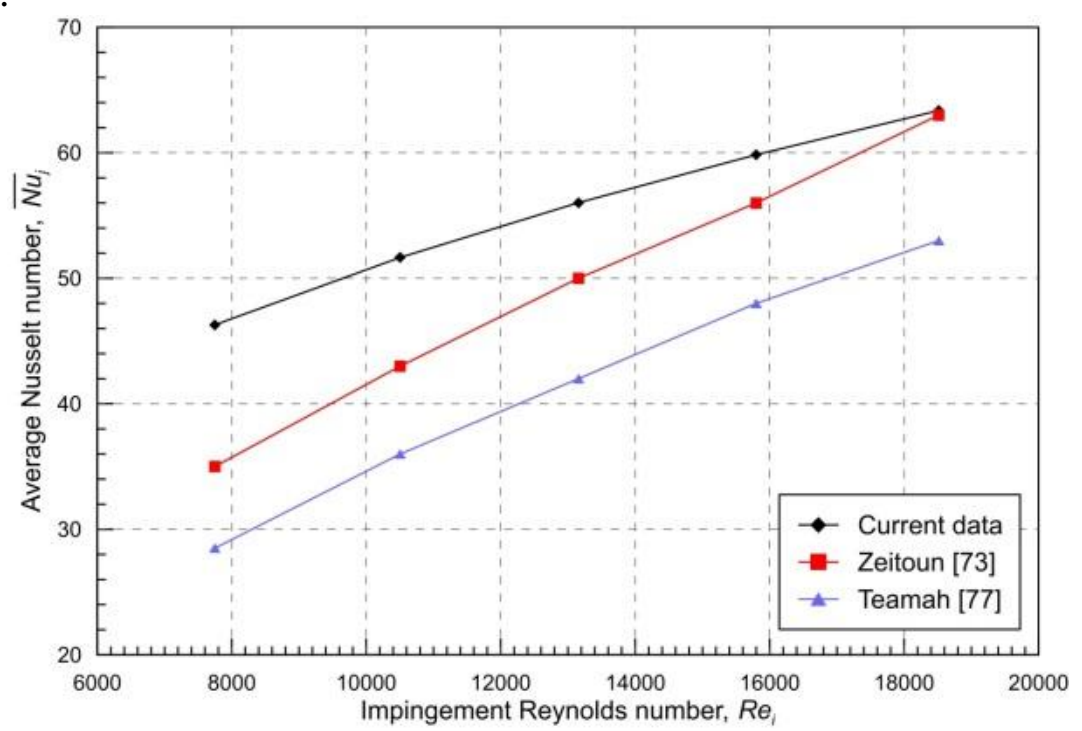

Figure 12:Effect of $\mathrm{Re}_{\mathrm{i}}$ on $\overline{N u} d$, for flat surface, $\mathrm{X}=0, \& \overline{\mathrm{T}_{\mathrm{Si}}}=175^{\circ} \mathrm{C}$

This figure shows that the two previous models under-predict the current experimental data by about $25 \%$ and $10.7 \%$ respectively, especially at $\operatorname{Re} i .13128$ 


\section{The influence of the plate's surface geometry, using distilled water}

Figure 13shows that increasing the surface area enhances the heat transfer between the cooling fluid and the plate. The figure shows that increasing the surface area increases $\overline{N u} d$. Increasing the surface area for the same flux increases the average heat transfer coefficient

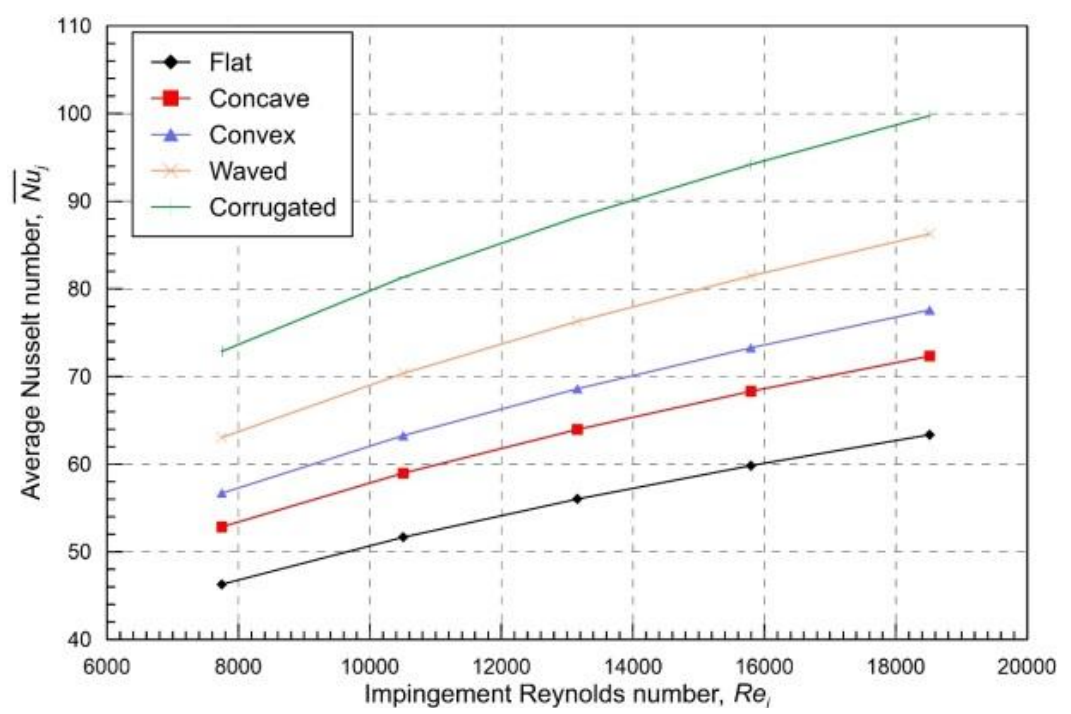

Figure 13:Effect of plate's surface geometry on $\overline{N u} d, \mathrm{X}=0, \& \overline{\mathrm{T}_{\mathrm{Si}}}=175^{\circ} \mathrm{C}$

This figure shows that changing the plate surface geometry from flat to corrugated increase $\overline{N u}_{d}$ by $58.7 \%$.

The influence of the plate's surface geometry, using $2 \%$ concentration nanofluid:-

Figure 14shows that increasing the surface area enhances the heat transfer between the cooling fluid and the plate that increases $\overline{N u}_{d}$. The figure shows that changing the plate surface geometry from flat to corrugated increases $\overline{N u}$; by $57.1 \%$, for the $2 \%$ concentration.

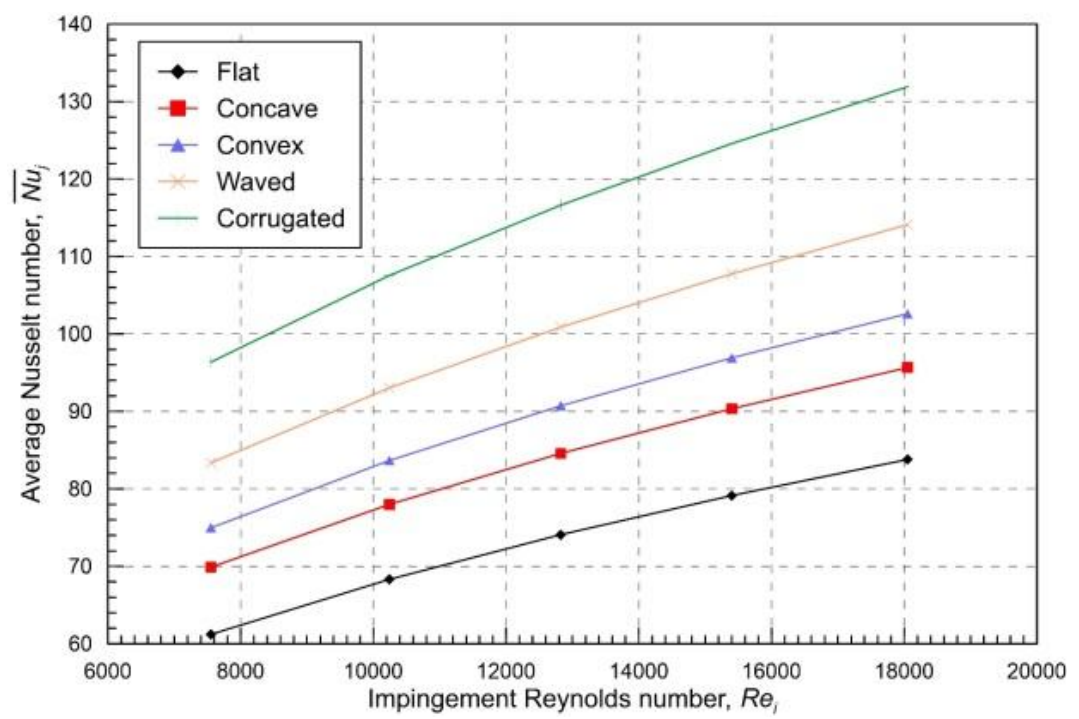

Figure 14:Effect of plate's geometry on $\overline{N u} d, \mathrm{X}=2.0 \%, \& \overline{\mathrm{T}_{\mathrm{Si}}}=175^{\circ} \mathrm{C}$

The kinematic viscosity of the $2 \% \mathrm{Al}_{2} \mathrm{O}_{3}$ concentration nanofluid is higher than that of distilled water by $2.58 \%$. This increase in kinematic viscosity decreases the impingement Reynolds number with a subsequent decrease in $\overline{N u}_{d}$. 


\section{The influence of $\mathrm{Al}_{2} \mathrm{O}_{3}$ concentration}

Figure 15 shows that, for the same concentration, increasing $R e_{i}$ increases $\overline{N u}_{j}$. Also, increasing the mass concentration of $\mathrm{Al}_{2} \mathrm{O}_{3}$ increases $\overline{N u}_{d}$ by $32.2 \%$

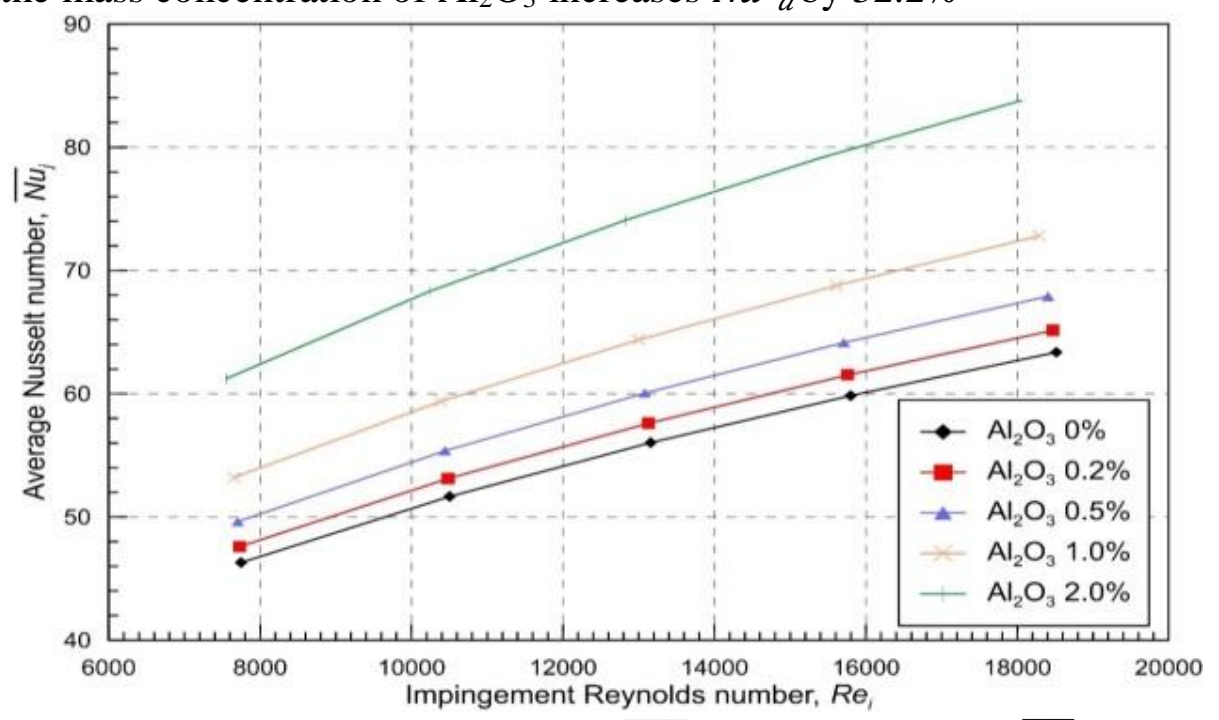

Figure 15:Effect of $\mathrm{Al}_{2} \mathrm{O}_{3}$ fraction on $\overline{N u} d$, for flat surface $\& \overline{\mathrm{T}_{\mathrm{Si}}}=175^{\circ} \mathrm{C}$

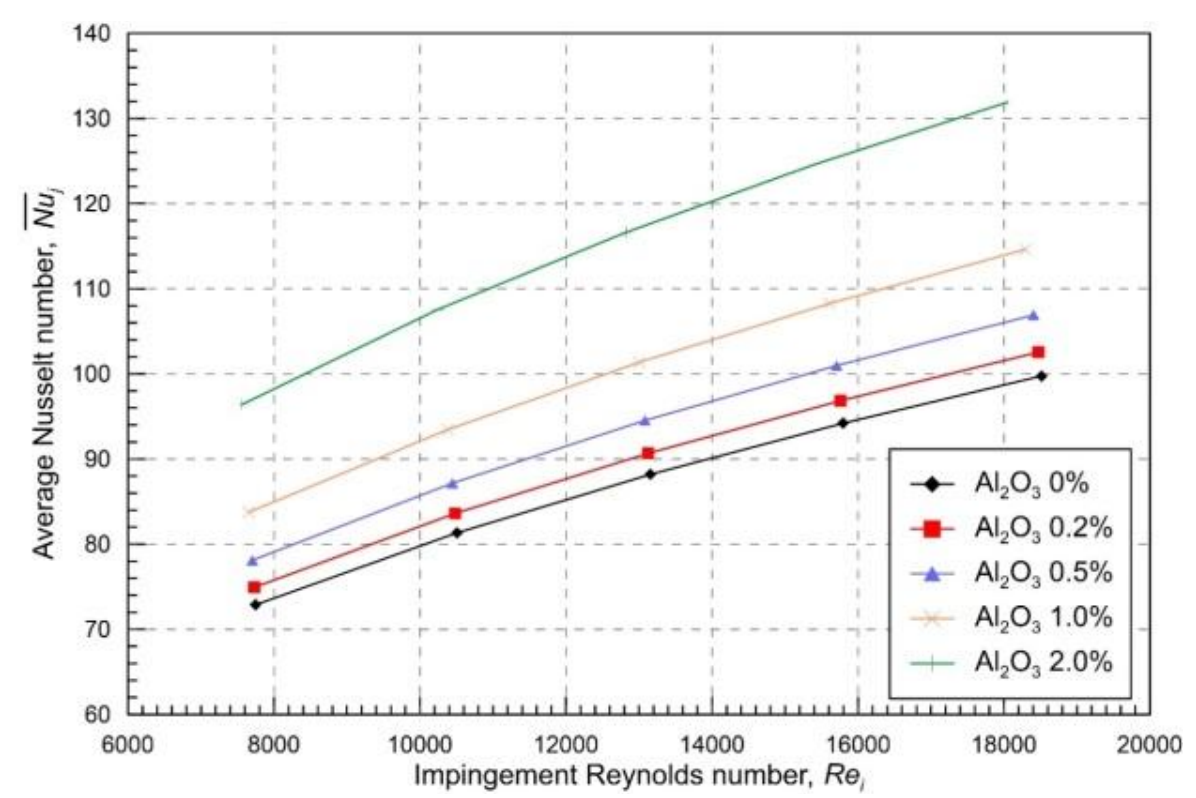

Figure 16:Effect of $\mathrm{Al}_{2} \mathrm{O}_{3}$ fraction on $\overline{N u} d$, for corrugated surface $\& \overline{\mathrm{T}}_{\mathrm{Si}}=175^{\circ} \mathrm{C}$

Figure 16shows that increasing the concentration of $\mathrm{Al}_{2} \mathrm{O}_{3}$ decreases $R e_{i}$, This is due to the increase in the kinematic viscosity of the nanofluid,increasing $R e_{i}$ increases $\overline{N u}_{j}$.

\section{The influence of adding dispersant (Polyethylene glycol) to $\mathrm{Al}_{2} \mathrm{O}_{3}$ nanofluid}

Figure 17shows the effect of adding Poly ethylene glycol (PEG) on the enhancement of heat transfer between the jet and the heated copper plate with different geometries, with $2 \%$ $\mathrm{Al}_{2} \mathrm{O}_{3}$ concentrations, in terms of the impingement Reynolds number and the average Nusselt number. 


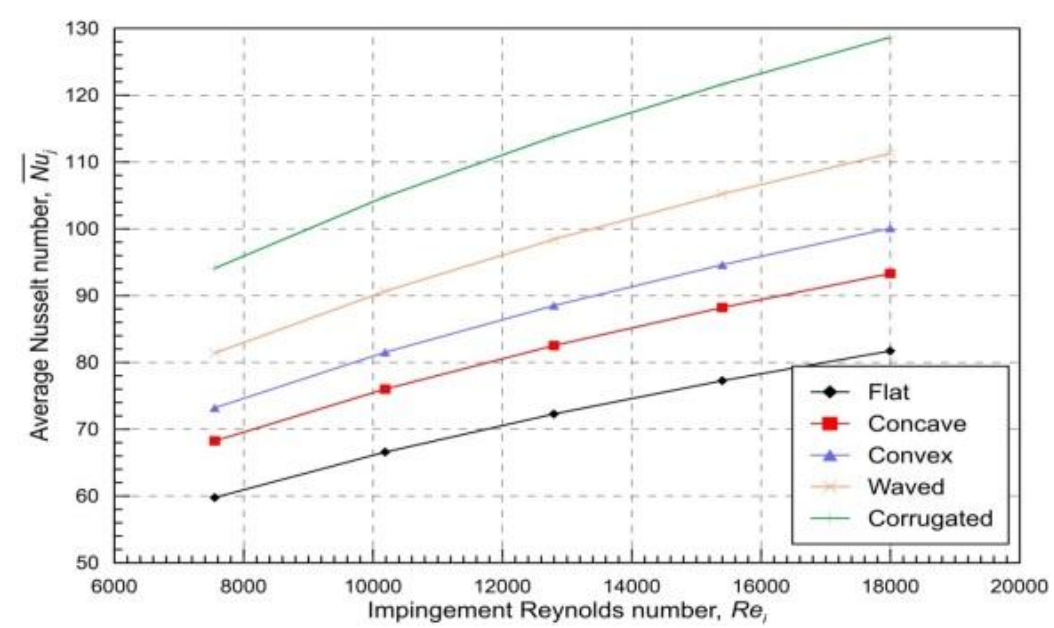

Figure 17:Effect of plate's geometry on $\overline{N u} d, \mathrm{X}=2.0 \%$, with PEG $600 \& \overline{\mathrm{T}_{\mathrm{Si}}}=175^{\circ} \mathrm{C}$

Thisfigure shows that adding dispersant (PEG 600) to $\mathrm{Al}_{2} \mathrm{O}_{3}$ decreases heat transfer by $2.5 \%$ but keeps suspension state and prevent agglomeration.

\section{CONCLUSION}

Increasing the volume flow rate of the cooling fluid decreases the cooling time by $26.76 \%$ and enhances the Nusselt number by $36.8 \%$.

using nanofluid jet enhances the heat transfer that may reach up to $32.2 \%$ at $2 \%$ concentration in all gometries.

Increasing the surface area enhances the heat transfer between the cooling fluid and the plate and decreases the cooling time.

The corrugated plate has the shortest cooling time, with a cooling time that is less than the flat surface by $38.5 \%$.

Changing plate surface shape can enhance heat transfer by $58.7 \%$ in case of water jet and by $57.1 \%$ in case of nanofluid jet with concentration $2 \%$.

The accumulative effect of using nanafluid jet $2 \%$ in corrugated surface with higher flow rate on Nusselt number can reach $185 \%$ compared with water jet on flat surface with lower flow rate.

The obtained correlation is:-

$$
\overline{N u}_{d}=P e_{i}{ }^{0.36}(1-X)^{-14.1} A_{r}{ }^{a}
$$

Where $A_{r}$ is the relative area defined as $A_{r}=D_{j}^{2} / 4 r^{2}$, where $D_{j}$ is the nozzle diameter and $r$ is the impingement surface radius and constant a equal as the following:-

For flat plate surface geometry zero, For concave plate surface geometry -0.0204 , For convex plate surface geometry -0.0312 , For waved plate surface geometry- 0.0474 and For corrugated plate surface geometry -0.0696 .

On the other hand, using a dispersant for the nanofluid as polyethylene glycol keeps the nanofluidsuspension and prevents agglomeration, but reduces its heat transfer enhancement effect.

\section{RECOMMENDATIONS:}

The experiments are performed using different volume flow rates and initial plate temperatures However, further research is required to address other issues including the following:

Using suitable numerical model to study the effect of nanofluid Jet Impingement on Heat Transfer of Surfaces with different Shapes.

Study the effect of different types of jets on heat transfer enhancement. 
Study the effect of different jet diameters on heat transfer enhancement.

Study the effect of different types of nanofluids on heat transfer enhancement.

Study the effect of other shapes of the heating surface on heat transfer enhancement.

\section{Symbols and Abbreviations}

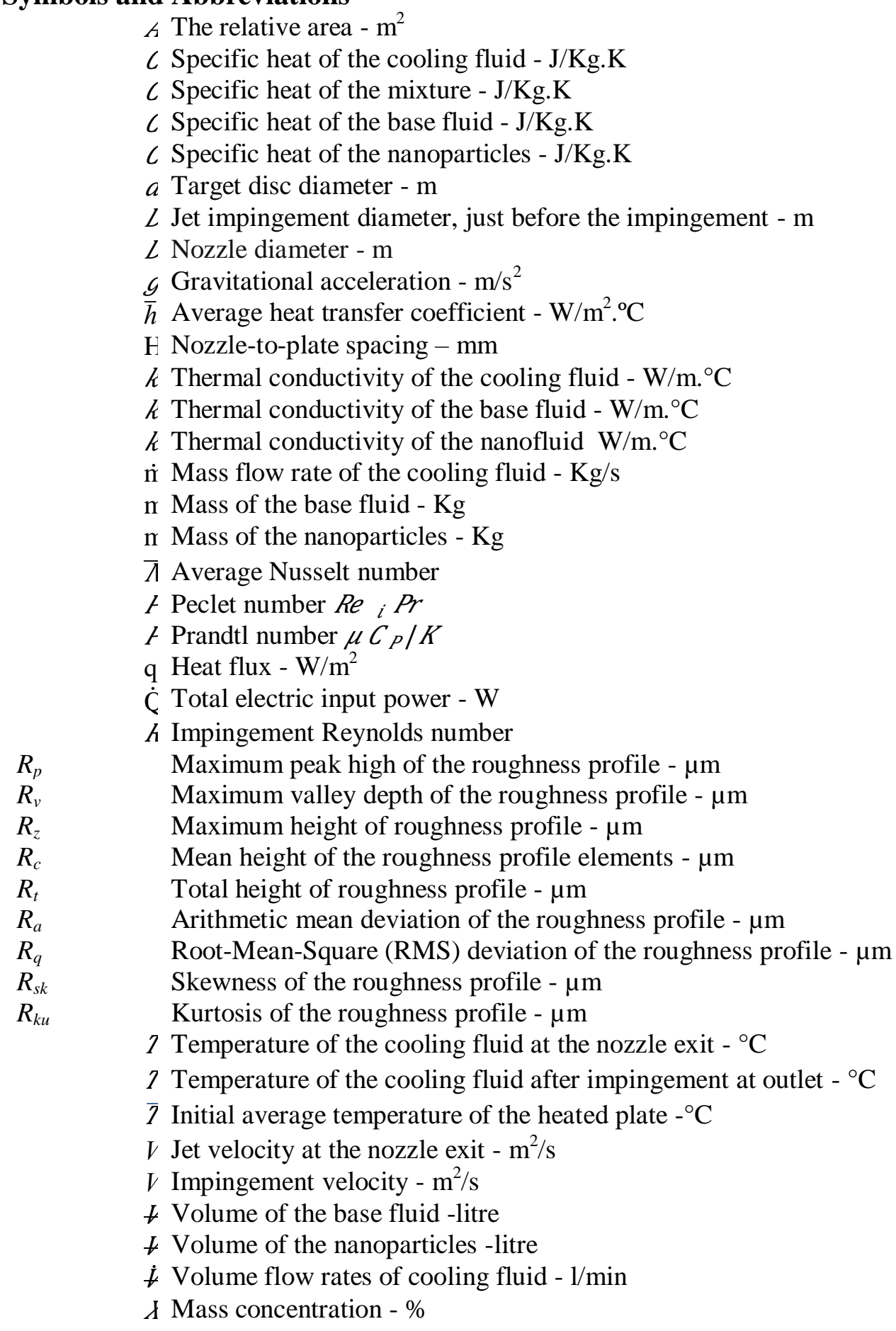

\section{Greek Symbols}

$\mu$ Dynamic viscosity of the cooling fluid - Kg/m.s

$\mu$ Dynamic viscosity of the base fluid $-\mathrm{Kg} / \mathrm{m} . \mathrm{s}$

$\mu$ Dynamic viscosity of the nanofluid- $\mathrm{Kg} / \mathrm{m} . \mathrm{s}$

$\nu$ Kinematic viscosity of the cooling fluid $-\mathrm{m}^{2} / \mathrm{s}$

$\imath$ Kinematic viscosity of the nanofluid $-\mathrm{m}^{2} / \mathrm{s}$ 
$\rho$ Density of the cooling fluid $-\mathrm{Kg} / \mathrm{m}^{3}$

$\rho$ Density of the base fluid $-\mathrm{Kg} / \mathrm{m}^{3}$

$\rho$ Density of the nanofluid- $\mathrm{Kg} / \mathrm{m}^{3}$

$\rho$ Density of the nanoparticles $-\mathrm{Kg} / \mathrm{m}^{3}$

4 Volume concentration - \%

\section{Abbreviations}

$\begin{array}{ll}\text { AFM } & \text { Atomic force microscopy } \\ \text { CHF } & \text { Critical heat flux } \\ \text { DI } & \text { Deionized } \\ \text { PEG } & \text { Polyethylene glycol } \\ \text { SEM } & \text { Scanning electron microscopy } \\ \text { TEM } & \text { Transmission electron microscopy } \\ \text { vol\% } & \text { Percentage volume concentration } \\ \text { XRD } & \text { X-ray powder diffraction }\end{array}$

\section{REFERENCES}

1. P. Anand, K. Lam, and K. A. Prakash, "Thermodynamic investigation and multiobjective optimization for jet impingement cooling system with $\mathrm{Al}_{2} \mathrm{O}_{3}$ /water nanofluid," Energy Convers. Manag., vol. 111, pp. 38-56, 2016.

2. R. Gugulothu, K. V. KumarReddy, S. S. Naga, and E. L. Adithya, "A Review on Enhancement of Heat Transfer Techniques; Volume 4,” Issue, vol. 2 Part A, pp. 10511056, 2017.

3. O. Manca, Y. Jaluria, and D. Poulikakos, "Heat Transfer in Nanofluids," Adv. Mech. Eng., vol. 2, p. 380826, 2010.

4. C. Maradiya, J. Vadher, and R. Agarwal, "The heat transfer enhancement techniques and their Thermal Performance Factor," Beni-Suef Univ. J. Basic Appl. Sci., vol. 7, no. 1, pp. 1-21, Mar. 2018.

5. D. Dey, P. Kumar, and S. Samantaray, "A review of nanofluid preparation, stability, and thermo-physical properties," Heat Transf. Res., vol. 46, no. 8, pp. 1413-1442, Dec. 2017.

6. Stephen . U. S. Choi and J. A. Eastman, "Enhancing thermal conductivity of fluids with nanoparticles," ASME International Mechanical Engineering Congress \& Exposition, San Francisco, CA. pp. 2-9, November 12-17, 1995.

7. S. Mukherjee and S. Paria, "Preparation and Stability of Nanofluids-A Review," IOSR J. Mech. Civ. Eng. (IOSR-JMCE, vol. 9, no. 2, pp. 63-69, 2013.

8. X.-Q. Wang and A. S. Mujumdar, "A review on nanofluids - part II: experiments and applications," Brazilian J. Chem. Eng., vol. 25, no. 4, pp. 631-648, Dec. 2008.

9. C. T. Nguyen, G. Roy, C. Gauthier, and N. Galanis, "Heat transfer enhancement using $\mathrm{Al}_{2} \mathrm{O}_{3}$-water nanofluid for an electronic liquid cooling system," Appl. Therm. Eng., vol. 27, no. 8-9, pp. 1501-1506, Jun. 2007.

10. K. Shukla and A. Dewan, "Flow and thermal characteristics of jet impingement: comprehensive review," Int. J. Heat Technol., vol. 35, no. 1, pp. 153-166, 2017.

11. J. H. Lienhard V and J. Hadeler, "High Heat Flux Cooling by Liquid Jet-Array Modules," Chem. Eng. Technol., vol. 22, no. 11, p. 967, Nov. 1999.

12. K. C. Jagtap, N. B. Kale, V. V Kale, K. S. Pawar, and S. A. Deshmukh, "Heat Transfer Enhancement Through Liquid Jet Impingement," Int. Res. J. Eng. Technol., vol. 10, pp. 2395-56, 2017.

13. G. Roy, I. Gherasim, F. Nadeau, G. Poitras, and C. T. Nguyen, "Heat transfer performance and hydrodynamic behavior of turbulent nanofluid radial flows," Int. J. Therm. Sci., vol. 58, pp. 120-129, Aug. 2012. 
14. C. H. Li and G. P. Peterson, "Experimental investigation of temperature and volume fraction variations on the effective thermal conductivity of nanoparticle suspensions (nanofluids)," J. Appl. Phys., vol. 99, no. 8, p. 084314, Apr. 2006.

15. C. T. Nguyen, G. Laplante, M. Cury, and G. Simon, "Experimental investigation of impinging jet heat transfer and erosion effect using $\mathrm{Al}_{2} \mathrm{O}_{3}$-water nanofluid," in Proceedings of the 6th IASME/WSEAS International Conference on Fluid Mechanics and Aerodynamics (FMA'08), pp. 44-48,August 20-22, 2008.

16. C. H. Li and G. P. Peterson, "Experimental investigation of temperature and volume fraction variations on the effective thermal conductivity of nanoparticle suspensions (nanofluids)," J. Appl. Phys., vol. 99, no. 8, p. 084314, Apr. 2006.

17. P. Keblinski, S. R. Phillpot, S. U. S. Choi, and J. A. Eastman, "Mechanisms of heat flow in suspensions of nano-sized particles (nanofluids)," Int. J. Heat Mass Transf., vol. 45, no. 4, pp. 855-863, 2002.

18. C. T. Nguyen, N. Galanis, G. Polidori, S. Fohanno, C. V Popa, and A. Le Bechec, "An experimental study of a confined and submerged impinging jet heat transfer using $\mathrm{Al}_{2} \mathrm{O}_{3^{-}}$ water nanofluid," Int. J. Therm. Sci., vol. 48, no. 2, pp. 401-411, 2009.

19. P. Tie, Q. Li, and Y. Xuan, "Heat transfer performance of $\mathrm{Cu}--$ water nanofluids in the jet arrays impingement cooling system," Int. J. Therm. Sci., vol. 77, pp. 199-205, 2014.

20. F. Afroz and M. A. R. Sharif, "Numerical study of heat transfer from an isothermally heated flat surface due to turbulent twin oblique confined slot-jet impingement," Int. J. Therm. Sci., vol. 74, pp. 1-13, 2013.

21. O. Zeitoun and M. Ali, "Nanofluid impingement jet heat transfer," Nanoscale Res. Lett., vol. 7, no. 1, p. 139, 2012.

22. B. Jaberi, T. Yousefi, B. Farahbakhsh, and M. Z. Saghir, "Experimental investigation on heat transfer enhancement due to $\mathrm{Al}_{2} \mathrm{O}_{3}$--water nanofluid using impingement of round jet on circular disk," Int. J. Therm. Sci., vol. 74, pp. 199-207, 2013.

23. S. K. Nayak, P. C. Mishra, and S. K. S. Parashar, "Enhancement of heat transfer by water-- $\mathrm{Al}_{2} \mathrm{O}_{3}$ and water-- $\mathrm{TiO}_{2}$ nanofluids jet impingement in cooling hot steel surface," J. Exp. Nanosci., vol. 11, no. 16, pp. 1253-1273, 2016.

24. V. B. Jaware and G. P. Bhagat, "Heat transfer enhancement by using nanofluid jet impingement,” Int. J. Eng. Technol. Manag. Appl. Sci., vol. 3, no. 5, pp. 50-60, 2015.

25. M. A. Teamah, M. M. K. Dawood, and A. Shehata, "Numerical and experimental investigation of flow structure and behavior of nanofluids flow impingement on horizontal flat plate," Exp. Therm. Fluid Sci., vol. 74, pp. 235-246, 2016.

26. J.-B. Huang and J.-Y. Jang, "Numerical study of a confined axisymmetric jet impingement heat transfer with nanofluids," Engineering, vol. 5, no. 01, p. 69, 2013.

27. G. Roy, C. T. Nguyen, and P.-R. Lajoie, "Numerical investigation of laminar flow and heat transfer in a radial flow cooling system with the use of nanofluids," Superlattices Microstruct., vol. 35, no. 3-6, pp. 497-511, 2004.

28. I. Gherasim, G. Roy, C. T. Nguyen, and D. Vo-Ngoc, "Experimental investigation of nanofluids in confined laminar radial flows," Int. J. Therm. Sci., vol. 48, no. 8, pp. 14861493, 2009.

29. Pak, B.C., Cho, Y.I., "Hydrodynamic and heat transfer study of dispersed fluids with submicron metallic oxide particles. Experiment". Heat Transfer 11 (2), 151-170. 1998.

30. Masuda, H., Ebata, A., Teramae, K., Hishinuma, N., "Alteration of thermal conductivity and viscosity of liquid by dispersing ultrafine particles (dispersion of $\gamma-\mathrm{Al}_{2} \mathrm{O}_{3}, \mathrm{SiO}_{2}$ and $\mathrm{TiO}_{2}$ ultra-fine particles)." Netsu Bussei (in Japanese) 4 (4), 227-233.1993.

31. Hamilton, R.L., Crosser, O.K.," Thermal conductivity of heterogeneous two-component systems" I \& EC Fundamentals 1 (3), 187-191.1962. 